\title{
Queer Times
}

\author{
Karolina Sobel
}

Der Raum, in dem wir leben, durch den wir aus uns herausgezogen werden, in dem sich die Erosion unseres Lebens, unserer Zeit und unserer Geschichte abspielt, dieser Raum, der uns zernagt und auswäscht, ist selber auch ein heterogener Raum.

(Foucault 1967)

Foucaults Begriff hat mich inspiriert, Bilder und ihre Kontexte neu zu verstehen und sie in ihrer Darstellung als Heterotopien zu konzipieren. Nach Theorien von Michel Foucault leben wir gleichermaßen in einer Epoche der Gleichzeitigkeit, des Aneinanderreihens, der Nähe und Ferne, des Nebeneinanders ebenso wie des Zerstreuten. Heterotopien existieren einerseits nicht als reale Orte, anderseits können sie einen Raum darstellen, der nicht körperlich existiert oder der eine andere Dimension besitzt.

In meiner Arbeit habe ich mich in vielen Experimenten mit analogen Fotografien mit der Technik der Doppelbelichtung auseinandergesetzt. Dieses Verfahren nutze ich als Werkzeug zur Darstellung einer Illusion und Wunschvorstellung des wirklichen Raumes. Die Bilder zeigen Begegnungen mit befreundeten queeren Menschen, unbekannten Plätzen und Orten, an denen Kunst präsentiert wird. Vor allem wird die Relativität der abgebildeten ,Wahrheit' belichtet. Meine Intention ist dabei, eine Identität der Menschen und Orte aufzuheben, die unsichtbaren und unausgesprochenen Ängste zu visualisieren und durch eine Zusammenstellung in neuen Konstellationen die verdeckten Sinngehalte hervorzubringen. Dabei soll eine neue Art der visuellen Narration entwickelt werden, die die verdeckten Wahrheiten und die Überlagerung der Bedeutungsebenen hervorbringt. 

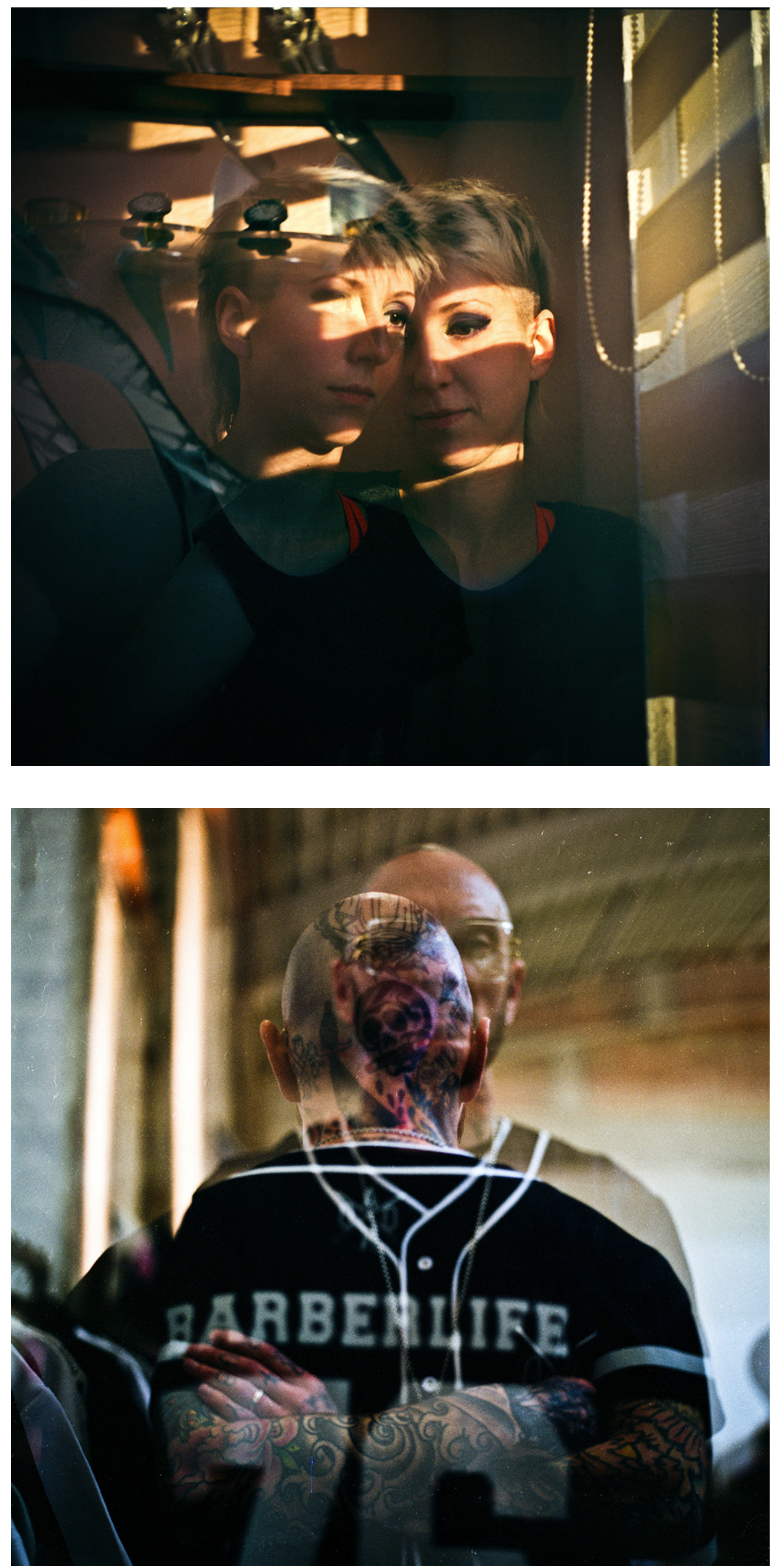

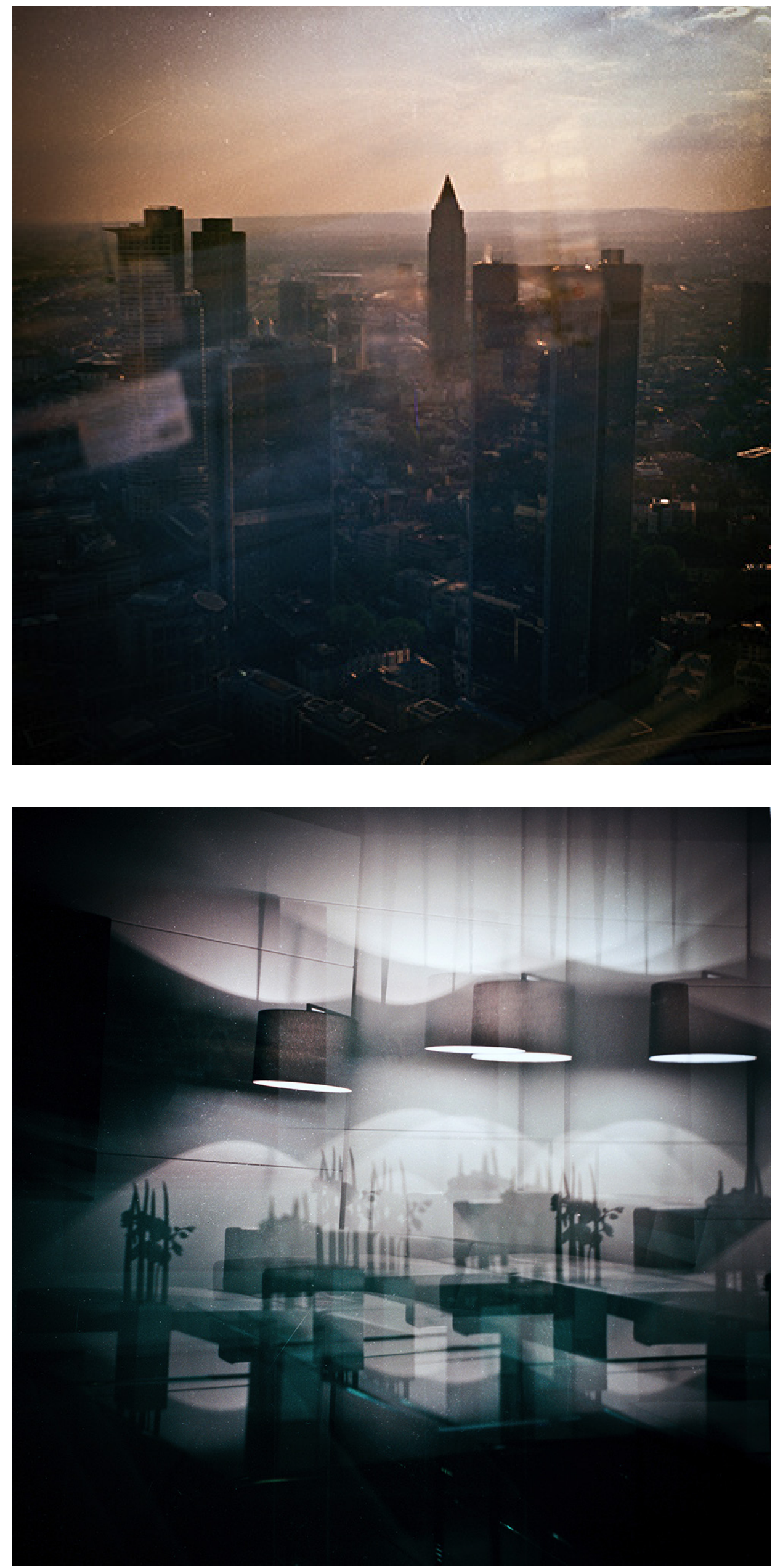

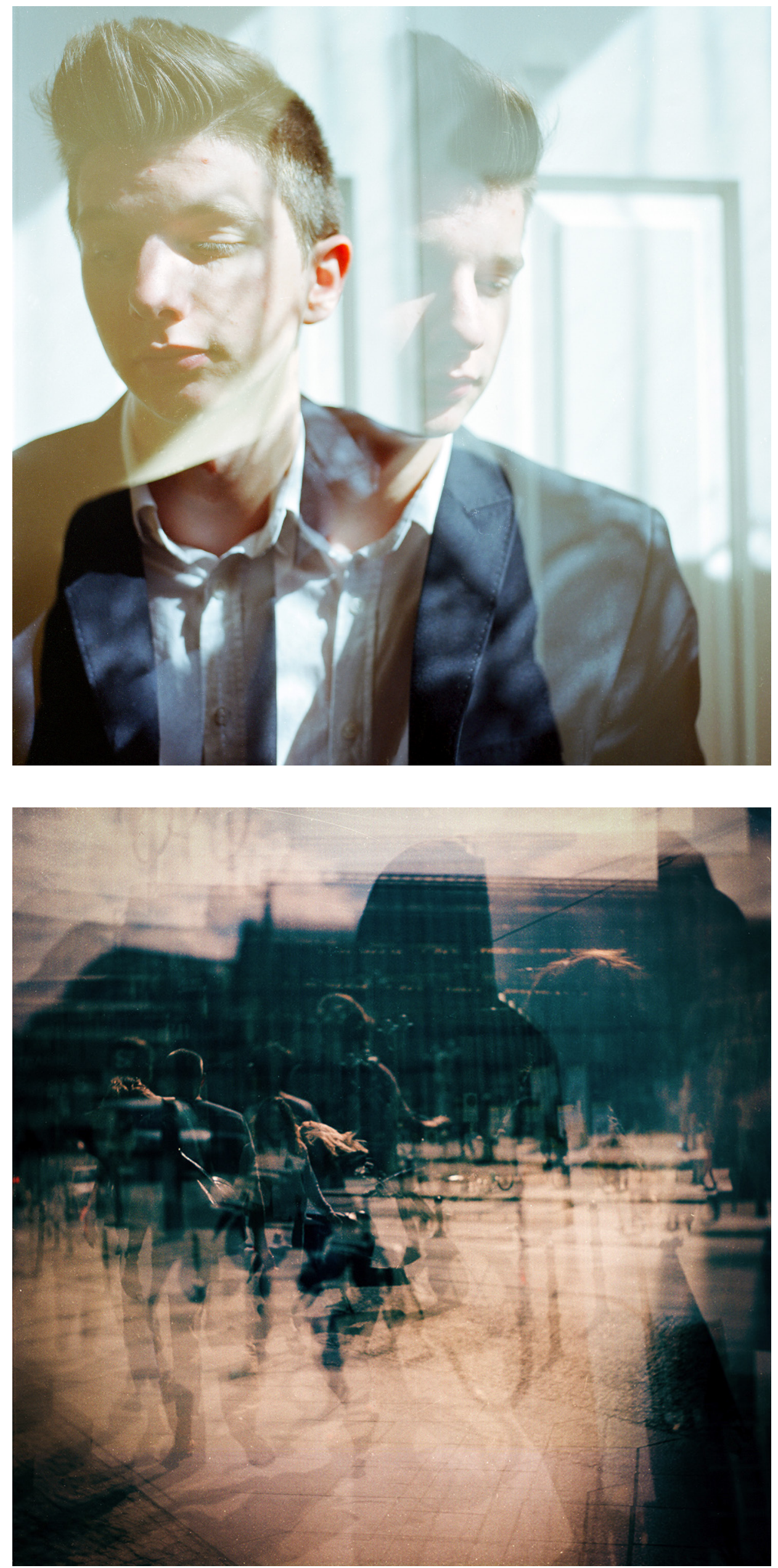

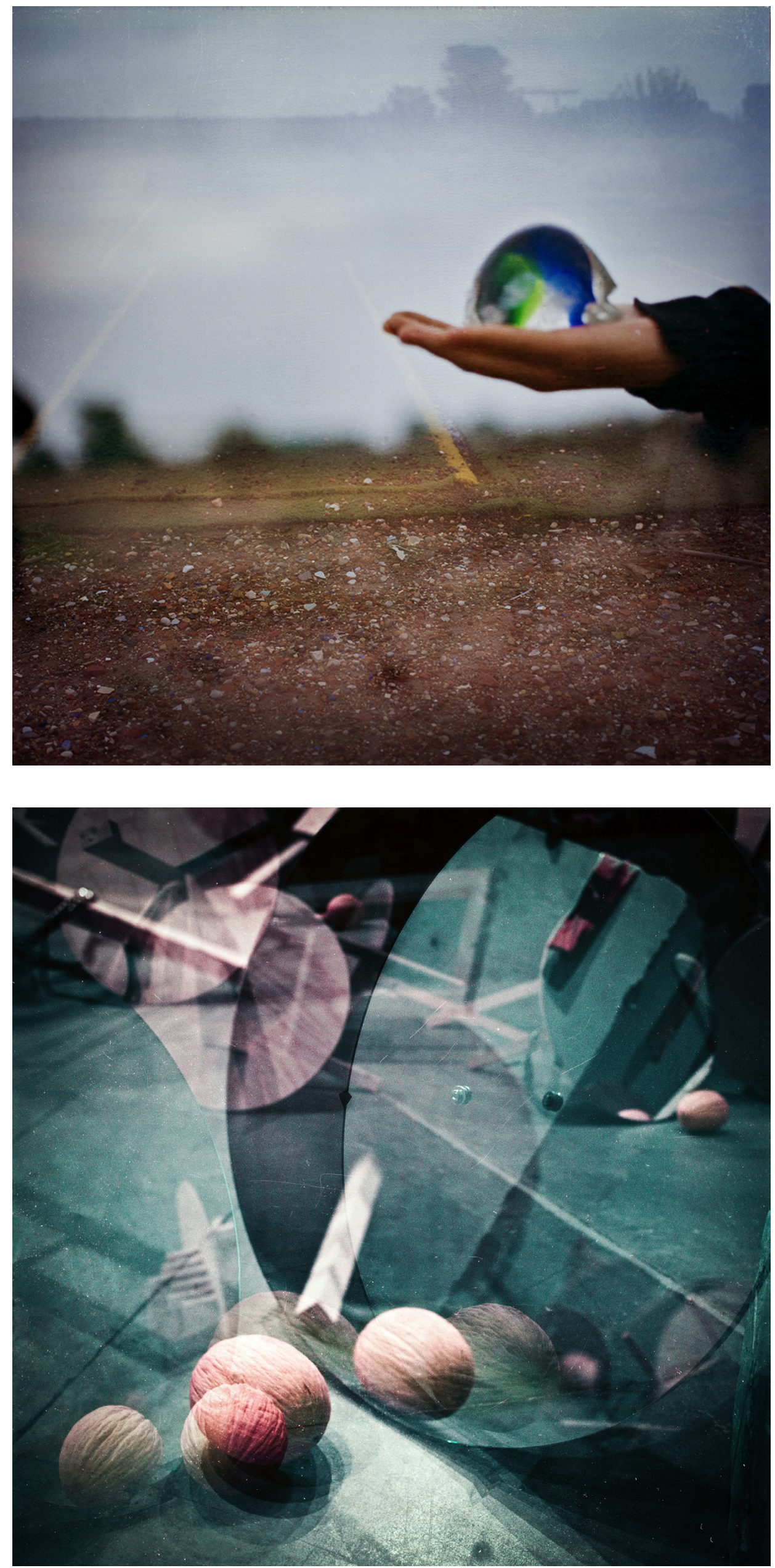


\section{Autor_innen}

Karolina Sobel absolvierte ein Studium der Stadtgeschichte und ist ausgebildete Fotofgrafin. Nach einem Auslandjahr in Paris (2012) lebt sie in Karlsruhe, widmet sich künstlerischen Projekten und studiert Medienkunst.

mail@karolinasobel.com

\section{Literatur}

Foucault, Michel (1993 [1967]): Andere Räume. In: Karlheinz Barck (Hg.): Aisthesis Wahrnehmung heute oder Perspektiven einer anderen Ästhetik; Essais. 5. Leipzig: Reclam, S. 39 